\title{
PEMBUATAN ARANG KOMPOS BIOAKTIF (ARKOBA) DARI LIMBAH PENYULINGAN NILAM
}

\section{(Manufacturing Bioactive Charcoal-Compost from Patchouli Distillation Wastes)}

\author{
Oleh/By: \\ Ahmad Junaedi ${ }^{1}$, Ahmad Rojidin ${ }^{2}$ \& Eko Sutrisno ${ }^{3}$ \\ ${ }^{1,2,3}$ Balai Penelitian Hutan Penghasil Serat, J1. HR. Soebrantas, Kuok, Riau, Tlp: (0762) 21370
}

Diterima 24 September 2007; disetujui 11 Agustus 2008

\begin{abstract}
Several orgadec dosages have been examined in producing nilam bioactive charcoal compost and obtaining the best formula. The experiment was accomplished using a completely randomized design with three levels of orgadec as the treatments. The orgadec dosages consisted of $2,5 \mathrm{~kg} / 100 \mathrm{~kg}(A 1), 5 \mathrm{~kg} / 100 \mathrm{~kg}$ (A2) and $7,5 \mathrm{~kg} / 100 \mathrm{~kg}$ of patchouli leave waste (A3), respectively. Composting duration of each dosages far 33 days showed that there were no different yields among the treatments applied. The nutrition content of each treatment product met the requirement of the compost quality standard. Treatment $A 1$ with lowest orgadec was considered the best composition with nutrition content of $\mathrm{N}=2,17 \% ; \mathrm{P}_{2} \mathrm{O}_{5}=1,5 \% ; \mathrm{K}_{2} \mathrm{O}=0,69 \% ; \mathrm{CaO}=0,84 \%$ and $\mathrm{C} / \mathrm{N}$ ratio $=9,4$, respectively.
\end{abstract}

Keywords: Orgadec, dosages, compost, nutrition content, patchouli

\begin{abstract}
ABSTRAK
Uji coba beberapa dosis orgadec pada pembuatan arang kompos bioaktif (arkoba) nilam dilakukan untuk memperoleh dosis orgadec terbaik. Untuk proses pengomposan rancangan acak lengkap digunakan dalam penelitian ini dengan menguji tiga dosis_orgadec sebagai perlakuan dan diulang tiga kali. Adapun perlakuannya adalah A1 $=$ dosis orgadec $2,5 \mathrm{k}, \mathrm{A} 2=5 \mathrm{~kg}$ dan A3 $=7,5 \mathrm{~kg}$ masing-masing untuk $100 \mathrm{~kg}$ bobot ampas penyulingan daun nilam. Hasil penelitian menunjukkan bahwa tidak ada perbedaan lama waktu pengomposan akibat perbedaan dosis orgadec. Pada semua perlakuan waktu pengomposan berlangsung selama 33 hari. Untuk keperluan efisiensi bahan bioaktivator, perlakuan A1 merupakan dosis yang terbaik dengan kandungan unsur hara : $\mathrm{N}=2,17 \%$; $\mathrm{P}_{2} \mathrm{O}_{5}=1,5 \% ; \mathrm{K}_{2} \mathrm{O}=0,69 \% ; \mathrm{CaO}=0,84 \%$ and $\mathrm{C} / \mathrm{N}$ ratio $=9,4$.
\end{abstract}

Kata kunci: Orgadec, arkoba, dosis, nilam, kandungan hara 


\section{PENDAHULUAN}

Sampai saat ini upaya diversifikasi hasil dari kegiatan industri kecil penyulingan daun nilam (PDN) masih dilakukan secara terbatas. Minyak nilam (patchouli oil) masih merupakan produk utama yang dihasilkan dari industri ini. Padahal, selain minyaknya dari PDN turut dihasilkan limbah penyulingan (ampas suling daun nilam) dengan volume yang sangat besar, tetapi belum banyak dimanfaatkan.

Pemanfaatan limbah PDN salah satunya bisa dilakukan melalui kegiatan pembuatan arang kompos bioaktif (arkoba). Kegiatan ini dapat mengatasi permasalahan lingkungan yang diakibatkan menumpuknya limbah penyulingan. Setiap kali penyulingan akan didapat limbah daun sekitar 95\% dari bahan yang disuling. Sementara itu arkoba nilam dapat diaplikasikan sebagai pupuk tanaman nilam maupun jenis tanaman lain. Saat ini kompos dijual dengan harga Rp. 500/kg (Hardja, 2008). Dengan harga jual ini adanya kegiatan pengomposan limbah PDN akan memberikan nilai tambah pada para petani nilam.

Teknologi pembuatan arkoba, diawali dengan penemuan teknologi pembuatan arang kompos oleh Puslitbang Hasil Hutan. Arang kompos adalah sejenis pupuk organik, berupa produk gabungan antara arang dan kompos yang dihasilkan melalui proses pengomposan (Gusmailina et al., 2006). Sedangkan kompos bioaktif adalah kompos yang diproduksi dengan bantuan mikroba lignoselulolitik unggul yang tetap bertahan di dalam kompos dan berperan sebagai agen hayati pengendali penyakit tanaman (Isroi, 2007). Dengan demikian maka arang kompos bioaktif (arkoba) merupakan arang kompos yang dihasilkan melalui proses pengomposan dengan memanfaatkan bio aktivator sebagai dekomposernya.

Salah satu bio aktivator yang dapat digunakan untuk membuat arkoba limbah PDN adalah orgadec. Orgadec merupakan bio aktivator yang mengandung mikroba dekomposer Trichoderma pseudokningii, Cytopaga sp dan fungi pelapuk putih (Isroi, 2007).

Selain bio aktivator, arang merupakan bahan penting pada pembuatan arkoba. Penambahan arang pada kompos akan memberikan beberapa keuntungan tersendiri. Adanya penambahan arang pada pembuatan arkoba (kompos) akan dapat memperkaya sifat dan unsur hara kompos sehingga menghasilkan kompos yang lebih berkualitas (Gusmailina et al., 2003). Adanya arang pada kompos diantaranya dapat meningkatkan $\mathrm{pH}$ dan kandungan karbon kompos. Keuntungan lainnya karena arang yang diberikan dapat berasal dari pemanfaatan limbah penyulingan dengan bahan bakar kayu. Selain itu arang dapat dibuat dari limbah pemungutan kayu (limbah eksploitasi kayu) maka penggunaan arang pada pembuatan arkoba akan mendukung program pengelolaan hutan yang mengarah pada zero waste.

Untuk menemukan teknik pembuatan arkoba limbah PDN yang efektif dan efisien salah satunya dapat dilakukan dengan melaksanakan uji coba beberapa dosis orgadec pada pembuatan arkoba limbah PDN. Diharapkan dengan uji coba tersebut diperoleh dosis orgadec (b/b) terbaik yang didasarkan kepada kriteria lamanya pengomposan dan kandungan unsur hara.

Tujuan penelitian ini adalah untuk mengetahui pengaruh dosis orgadec terhadap lama proses pengomposan dan kandungan unsur hara arkoba limbah PDN. 


\section{METODOLOGI}

\section{A. Waktu dan Tempat Penelitian}

Penelitian ini dilaksanakan selama sekitar dua bulan yaitu dari bulan Januari sampai dengan Pebruari 2007 di bak pengomposan permanen Balai Penelitian Hutan Penghasil Serat di Kuok, Kabupaten Kampar, Propinsi Riau.

\section{B. Bahan dan Alat}

Bahan dan alat yang digunakan dalam penelitian ini antara lain adalah : orgadec sebagai bio aktivator, ampas penyulingan daun nilam (ampas PDN), arang (limbah bahan bakar penyulingan), air, peralatan untuk mencampurkan bahan-bahan kompos, termometer, alat tulis dan alat-alat lainnya.

\section{Rancangan Percobaan}

Rancangan acak lengkap digunakan dalam penelitian ini dengan menguji tiga dosis orgadec yang dipilih sebagai perlakuan, dan diulang sebanyak tiga kali. Adapun perlakuannya adalah:

$\mathrm{A} 1=$ dosis orgadec $2,5 \mathrm{~kg} / 100 \mathrm{~kg}$ bobot ampas PDN (2,5\% dari bobot bahan); A2 = dosis orgadec $5 \mathrm{~kg} / 100 \mathrm{~kg}$ bobot ampas PDN (5\% dari bobot bahan) dan A3 = dosis orgadec $7,5 \mathrm{~kg} / 100 \mathrm{~kg}$ bobot ampas PDN (7,5\% dari bobot bahan).

\section{Pembuatan Arang Kompos Bioaktif Limbah Penyulingan Daun Nilam (Arkoba Nilam)}

Proses pembuatan arkoba nilam prinsipnya sama dengan pembuatan kompos biasa, namun dilengkapi dengan penambahan arang dan bio aktivator (orgadec). Adapun langkah pembuatannya adalah sebagai berikut:

1. Mencampur bahan kompos (ampas PDN) $100 \mathrm{~kg}$, arang $10 \mathrm{~kg}$, orgadec beratnya disesuaikan dengan dosis perlakuan yang dicobakan (2,5 kg untuk A1; $5 \mathrm{~kg}$ untuk A2 dan 7,5 kg untuk A3) dan air sekitar 30 liter. Semua bahan dicampurkan sampai merata.

2. Campuran tersebut dimasukkan ke dalam bak/wadah pengomposan yang sudah tersedia. Bagian atas ditutup dengan plastik, pada bagian tengah dipasang termometer sampai ke dalam tengah tumpukan kompos.

3. Suhu diukur setiap hari untuk memonitor proses pengomposan apakah berjalan atau tidak. Jika kecenderungan suhu tetap atau menurun maka dilakukan pembalikan kompos dan jika menjadi kering ditambahkan air. Indikator kompos sudah matang yaitu jika suhu sudah menurun dan setelah dilakukan pembalikan tidak mengalami kenaikan suhu kembali serta secara visual bahan kompos telah mengalami perubahan warna menjadi lebih gelap dan berbau mirip tanah.

4. Setelah kompos benar-benar matang dan tidak lagi mengalami perubahan/fluktuasi suhu, kompos dibongkar dan diangin-anginkan minimal 3 hari sebelum siap untuk diaplikasikan. 


\section{E. Pengamatan dan Pengumpulan Data}

Proses pengomposan dipengaruhi oleh beberapa faktor yaitu kelembaban, $\mathrm{pH}$, mikroorganisme dan suhu pengomposan (Djuarnani et al., 2005). Berdasarkan faktor-faktor tersebut untuk memantau laju pengomposan relatif mudah jika dilakukan dengan mengukur perubahan suhu selama pengomposan. Untuk itu selama berlangsungnya proses pengomposan, pada tiap perlakuan dilakukan pengukuran suhu campuran bahan arkoba nilam (CBAN). Pengukuran ini ditujukan untuk mengetahui perbedaan proses dekomposisi kompos akibat perbedaan dosis orgadec. Pengukurannya dilakukan pada semua bak pengomposan sehingga terdapat tiga ulangan pengamatan pada tiap perlakuan.

Suhu CBAN diukur dengan termometer pada bagian tengah tumpukan campuran bahan. Pengamatan dilakukan tiga kali sehari yaitu pada pkl. 08.00, pkl. 13.00 dan pkl. 16.00. Pada masing-masing perlakuan dan waktu pengamatan, pengukuran suhu dilakukan tiga kali ulangan. Pengamatan dibagi ke dalam tiga periode pengamatan yaitu periode I ( 1 hari pengomposan/HP sampai dengan $12 \mathrm{HP}$ ), periode II (13 HP sampai dengan $25 \mathrm{HP}$ dan periode III (26 HP sampai dengan $35 \mathrm{HP}$ ). Pembagian ini didasarkan oleh aktivitas dekomposisi oleh mikroorganisme (Djuarnani et al., 2005). Pengamatan dihentikan sampai suhu CBAN konstan yang mengindikasikan bahwa pembuatan arkoba nilam sudah selesai (sekitar satu bulan).

Selanjutnya pada tiap perlakuan diambil sample arkoba nilam untuk dianalisis kandungan unsur haranya di laboratorium tanah Balai Pengkajian Teknologi Pertanian (BPTP) Riau. Parameter yang dianalisa adalah sifat kimia arkoba dengan variabel-variabelnya : kandungan $\mathrm{C}$ dan $\mathrm{N}$ total yang dianalisa dengan metode Kjeldabl; kandungan $\mathrm{P}_{2} \mathrm{O}_{5}, \mathrm{~K}_{2} \mathrm{O}$ dan $\mathrm{CaO}$ yang dianalisa dengan metode penjenuhan Amonium acetat $\mathrm{pH}$ 7. Sample yang diambil pada tiap perlakuan merupakan sample campuran (komposit) dari tiga ulangan perlakuan sehingga terdapat tiga sample yang dianalisis.

Analisa laboratorium dilakukan juga terhadap sifat kimia bahan arkoba (limbah PDN) yang dilakukan sebelum pengomposan. Adapun sifat kimia yang dianalisa adalah : kandungan $\mathrm{C}$ dan $\mathrm{N}$ total dianalisa dengan metode Kjeldabl; $\mathrm{K}_{2} \mathrm{O}$ dan $\mathrm{CaO}$ yang dianalisa dengan metode penjenuhan Amonium acetat $\mathrm{pH} 7$.

\section{F. Analisa Data}

Analisa statistik dengan uji ANOVA dilakukan untuk mengetahui pengaruh perbedaan perlakuan terhadap perbedaan suhu selama pengomposan. Sementara analisa deskriptif dilakukan untuk mengetahui pengaruh perlakuan terhadap kandungan unsur hara ALPN.

\section{HASIL DAN PEMBAHASAN}

\section{A. Suhu Selama Pengomposan}

Hasil penelitian menunjukkan bahwa pada periode I (1 hari pengomposan/HP sampai dengan $12 \mathrm{HP}$ ) laju pengomposan berlangsung cepat yang ditunjukkan oleh laju peningkatan 
suhu yang pesat (Gambar 1). Peningkatan suhu tersebut disebabkan oleh adanya aktifitas perombakan bahan organik oleh mikro-organisme (Simamora dan Salundik, 2006). Pada periode II (1 HP sampai dengan $25 \mathrm{HP}$ ) suhu pengomposan cenderung menurun dan selanjutnya relatif stabil pada periode III (26 HP sampai dengan $35 \mathrm{HP}$ ). Hal ini menunjukkan bahwa pada periode II proses pengomposan mengalami penurunan dan berhenti pada periode III. Secara umum, kondisi tersebut berlangsung untuk perlakuan A1, A2 dan A3.

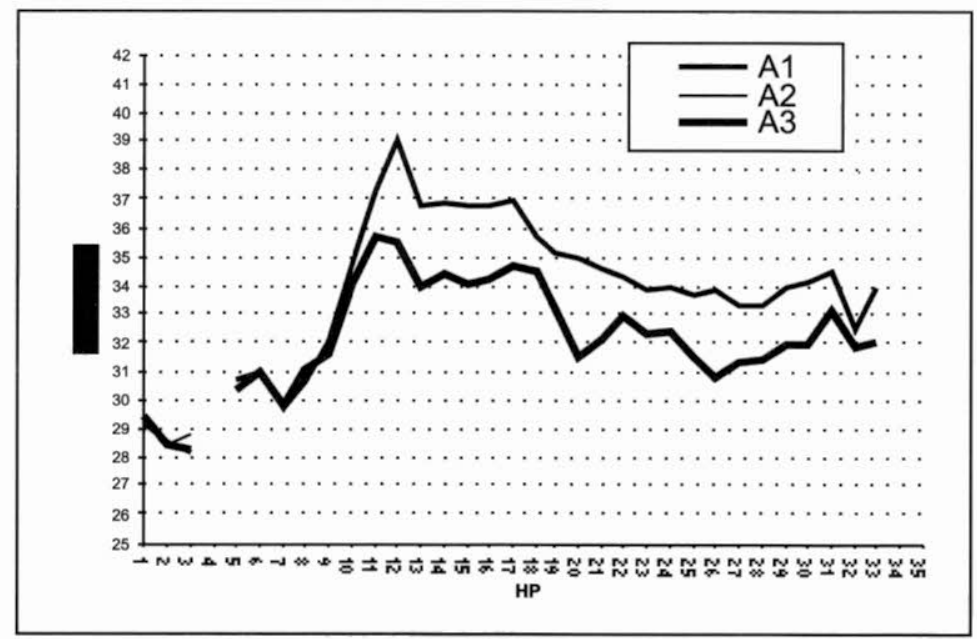

Keterangan (Remarks) : A1 = dosis orgadec $2,5 \mathrm{~kg} / 100 \mathrm{~kg}$ ampas penyulingan (orgadec dosage $2,5 \mathrm{~kg} / 100 \mathrm{~kg}$ of distilled waste); $\mathrm{A} 2=$ dosis orgadec $5 \mathrm{~kg} / 100 \mathrm{~kg}$ ampas penyulingan (orgadec dosage 5 $\mathrm{kg} / 100 \mathrm{~kg}$ of distilled waste); $\mathrm{A} 3=$ dosis orgadec $7,5 \mathrm{~kg} / 100 \mathrm{~kg}$ ampas penyulingan (orgadec dosage $7,5 \mathrm{~kg} / 100 \mathrm{~kg}$ of distilled waste); $\mathrm{HP}=$ hari pengomposan (days of composting)

\section{Gambar (Figure) 1. Suhu $\left({ }^{\circ} \mathrm{C}\right)$ selama pengomposan pada masing-masing perlakuan dosis orgadec (Temperatures of composting at several orgadec dosages level)}

Djuarnani et al. (2005) menyatakan bahwa pada kisaran suhu $35-55^{\circ} \mathrm{C}$ mikroorganisme sudah mampu untuk mendekomposisi bahan kompos. Walaupun idealnya dekomposisi akan berlangsung sempurna jika mencapai kisaran suhu $55-60^{\circ} \mathrm{C}$ (Gusmailina et al., 2006). Pada kisaran suhu tersebut, mikroorganisme dekomposer tumbuh tiga kali, enzim akan bekerja lebih efektif dan penurunan $\mathrm{C} / \mathrm{N}$ akan berlangsung sempurna.

Pada penelitian ini kisaran suhu tersebut tidak dapat dicapai. Suhu tertinggi yang dapat dicapai pada masing-masing perlakuan adalah $39,0^{\circ} \mathrm{C}$ untuk $\mathrm{A} 1,40,8^{\circ} \mathrm{C}$ untuk $\mathrm{A} 2$ dan $35,7^{\circ} \mathrm{C}$ untuk A3. Tidak tercapainya suhu tertinggi pada kisaran $55-60^{\circ} \mathrm{C}$ disebabkan oleh beberapa faktor antara lain adalah: kurang tingginya tumpukan campuran bahan arkoba $(<1 \mathrm{~m})$, jenis bahan arkoba yang digunakan dan pengaruh tingginya curah hujan selama pengomposan. Pada tumpukan bahan yang terlalu rendah $(<1 \mathrm{~m})$ bahan kompos akan cepat kehilangan panas sehingga suhu yang tinggi tidak tercapai (Djuarnani et al., 2005). 


\section{Tabel1. Suhu selama pengomposan $\left({ }^{\circ} \mathrm{C}\right)$ pada tiap perlakuan untuk tiap periode pengamatan}

\section{Table 1. Composting temperature of each dosages on different periods}

\begin{tabular}{|c|c|c|c|c|}
\hline \multirow{2}{*}{ Perlakuan } & \multicolumn{4}{|c|}{ Suhu pengomposan(Composting temperature $)$} \\
\cline { 2 - 5 }$($ Treatment $)$ & $\begin{array}{c}\text { Periode I } \\
\left(1^{\text {st }} \text { period }\right)\end{array}$ & $\begin{array}{c}\text { Periode II } \\
\left(2^{\text {nd }} \text { period }\right)\end{array}$ & $\begin{array}{c}\text { Periode III } \\
\left(3^{\text {rd }} \text { period }\right)\end{array}$ & $\begin{array}{c}\text { Rataan } \\
(\text { Average })\end{array}$ \\
\hline $\mathrm{A} 1$ & $(31.7 \pm 2.4) \mathrm{a}$ & $(35.7 \pm 1.9) \mathrm{b}$ & $(33.5 \pm 1.5) \mathrm{c}$ & $(33.6 \pm 1.8) \mathrm{d}$ \\
\hline $\mathrm{A} 2$ & $(31.8 \pm 2.2) \mathrm{a}$ & $(35.7 \pm 2.2) \mathrm{b}$ & $(33.3 \pm 1.2) \mathrm{c}$ & $(33.6 \pm 1.8) \mathrm{d}$ \\
\hline $\mathrm{A} 3$ & $(31.3 \pm 1.9) \mathrm{a}$ & $(33.4 \pm 0.3) \mathrm{b}$ & $(31.8 \pm 0.6) \mathrm{c}$ & $(32.1 \pm 0.4) \mathrm{d}$ \\
\hline $\begin{array}{c}\text { Rataan } \\
\text { (Average })\end{array}$ & $(31.6 \pm 0.3)$ & $(34.9 \pm 1.3)$ & $(32.9 \pm 0.9)$ & $(33.1 \pm 0.9)$ \\
\hline
\end{tabular}

Keterangan (Remarks) : Angka yang diikut huruf yang sama dalam satu kolom tidak berbeda nyata berdasarkan uji ANOVA taraf $5 \%$ (The numbers was followed by the same letters are not significantly different at $5 \%$ level with ANOVA test); $\mathrm{A} 1=$ dosis orgadec $2,5 \mathrm{~kg} / 100 \mathrm{~kg}$ ampas penyulingan (orgadec dosage $2,5 \mathrm{~kg} / 100 \mathrm{~kg}$ of distilled waste); A2 = dosis orgadec $5 \mathrm{~kg} / 100 \mathrm{~kg}$ ampas penyulingan (orgadec dosage $5 \mathrm{~kg} / 100 \mathrm{~kg}$ of distilled waste); $\mathrm{A} 3=$ dosis orgadec $7,5 \mathrm{~kg} / 100 \mathrm{~kg}$ ampas penyulingan (orgadec dosage $7,5 \mathrm{~kg} / 100 \mathrm{~kg}$ of nilam distilled waste)

Berdasarkan analisis statistik dengan uji ANOVA tidak ada perbedaan yang nyata $(\mathrm{p}<0,05)$ perubahan suhu selama proses pengomposan (seluruh periode pengamatan) akibat perbedaan dosis orgadec (Tabel 1). Kondisi ini menunjukkan bahwa berdasarkan indikator suhu pengomposan laju pengomposan pada perlakuan $\mathrm{A} 1, \mathrm{~A} 2$ dan $\mathrm{A} 3$ berlangsung relatif sama yaitu selama 33 hari.

\section{B. Kandungan Unsur Hara}

Hasil analisa unsur hara yang dikandung oleh arkoba nilam pada tiap perlakuan orgadec dapat dilihat pada Tabel 2. Pada Tabel 2 nampak tidak terdapat pola yang konsisten untuk kandungan unsur hara akibat perbedaan dosis orgadec. Pada dosis orgadec yang dicobakan, peningkatan dosis cenderung tidak diikuti oleh peningkatan kandungan unsur hara arkoba. Dengan hasil tersebut berdasarkan indikator kandungan unsur hara maka kualitas arkoba pada tiap perlakuan relatif sama. Dengan demikian karena tidak ada perbedaan kandungan unsur hara maka dari segi efisiensi bahan aktivator, dosis orgadec A1 merupakan dosis terbaik untuk diaplikasikan.

Dibandingkan kompos limbah nilam yang dibuat dengan campuran Em4 (1\%), pupuk kandang dan kapur yang dilaporkan Djazuli \& Trisilawati (2004) secara umum, kandungan unsur hara arkoba nilam memiliki kandungan unsur hara yang lebih rendah. Hal ini berarti dari segi kandungan hara, kualitas kompos limbah PDN tersebut cenderung lebih baik daripada arkoba nilam. Hal tersebut dimungkinkan karena adanya tambahan unsur hara dari pupuk kandang dan kapur. Adanya fraksi kapur terutama menyebabkan tingginya kandungan $\mathrm{CaO}(1,7 \%)$ dan $\mathrm{K}_{2} \mathrm{O}(1,26 \%)$, sedangkan pupuk kandang menyebabkan tinggginya kandungan karbon dan nitrogen. Dari hasil perbandingan tersebut maka untuk lebih meningkatkan kandungan unsur hara dapat direkomendasikan penambahan kapur pada pembuatan arkoba nilam. 
Tabel2. Kandungan unsur hara pada arkoba nilam, kompos limbah penyulingan daun nilam dan arang kompos sebuk gergaji

Table 2. The Nutrition Content of nilam bioactive charcoal compost, nilam leaves distilled waste compost and charcoal compost of wood wastage

\begin{tabular}{|c|c|c|c|c|c|}
\hline \multirow{2}{*}{$\begin{array}{l}\text { Kandungan hara } \\
\text { (Nutrition content) }\end{array}$} & \multicolumn{3}{|c|}{$\begin{array}{c}\text { Arkoba nilam (nilam bio active charcoal } \\
\text { compost) }\end{array}$} & \multirow{2}{*}{$\begin{array}{l}\text { Kompos nilam (nilam } \\
\text { distilled waste compost) }\end{array}$} & \multirow[t]{2}{*}{$\mathrm{AKSG}^{\mathrm{b}}$} \\
\hline & A1 & $\mathrm{A} 2$ & A3 & & \\
\hline $\mathrm{pH}\left(\mathrm{H}_{2} \mathrm{O}\right)$ & 8,70 & 8,90 & 8,70 & - & - \\
\hline $\mathrm{C}(\%)$ & 20,4 & 20,20 & 22,32 & 35,70 & 43,61 \\
\hline $\mathrm{N}(\%)$ & 2,17 & 2,17 & 2,09 & 3,59 & 1,74 \\
\hline $\mathrm{C} / \mathrm{N}$ & 9,40 & 9,31 & 10,68 & 9,94 & 25,06 \\
\hline $\mathrm{P}_{2} \mathrm{O}_{5}(\%)$ & 1,50 & 1,52 & 1,34 & 0,28 & 0,58 \\
\hline $\mathrm{K}_{2} \mathrm{O}(\%)$ & 0,69 & 0,74 & 0,77 & 1,26 & 0,42 \\
\hline $\mathrm{CaO}(\%)$ & 0,84 & 0,13 & 0,85 & 1,70 & 2,76 \\
\hline
\end{tabular}

Keterangan (Remarks) $: \mathrm{A} 1=$ dosis orgadec $2,5 \mathrm{~kg} / 100 \mathrm{~kg}$ ampas penyulingan (orgadec dosage $2,5 \mathrm{~kg} / 100 \mathrm{~kg}$ of distilled wastage); $\mathrm{A} 2=$ dosis orgadec $5 \mathrm{~kg} / 100 \mathrm{~kg}$ ampas penyulingan (orgadec dosage $5 \mathrm{~kg} / 100 \mathrm{~kg}$ of distilled wastage); $\mathrm{A} 3=$ dosis orgadec $7,5 \mathrm{~kg} / 100 \mathrm{~kg}$ ampas penyulingan (orgadec dosage $7,5 \mathrm{~kg} / 100 \mathrm{~kg}$ of distilled wastage); " = Djazuli \& Trisilawati (2004); = campuran limbah penyulingan + EM4 $(1 \%)+$ pupuk kandang + kapur (mixed of distilled wastage $+1 \%$ EM4 + poultry wastage + farming lime); $\mathrm{AKSG}=$ arang kompos serbuk gergaji (charcoal compost of wood wastage); $\mathrm{b}=$ sumber/refer to Gusmailina et al. (2000) dalam/in Gusmailina et al. (2003)

Walaupun kandungan unsur hara arkoba nilam cenderung lebih rendah daripada kompos limbah penyulingan nilam, namun pada tahap aplikasi adanya fraksi arang pada arkoba akan memberikan manfaat lebih bagi kondisi tanah dan pertumbuhan tanaman. Gusmailina et al. (2003) menyatakan bahwa adanya arang pada kompos akan dapat meningkatkan $\mathrm{pH}$ tanah, menjaga hara tanah tidak mudah tercuci dan dapat memperbaiki sifat fisik tanah. Sementara itu, Siregar (2007) melaporkan bahwa pemberian arang $10 \%$ (v/v) pada media pembibitan dari campuran tanah jenis acrisol dan nitosol, secara nyata meningkatkan pertumbuhan tinggi dan diameter bibit Acacia mangium dan Michelia montana.

Sementara itu, dibandingkan dengan kandungan unsur hara arang kompos serbuk gergaji (AKSG) yang dilaporkan oleh Gusmailina et al. (2000) dalam Gusmailina et al. (2003), beberapa unsur hara pada arkoba nilam lebih tinggi dibandingkan arang kompos tersebut. Nampak bahwa kandungan $\mathrm{N}(\%), \mathrm{P}_{2} \mathrm{O}_{5}(\%)$ dan $\mathrm{K}_{2} \mathrm{O}(\%)$ pada arkoba nilam lebih tinggi dibandingkan AKSG. Perbedaan kandungan hara kompos tersebut disebabkan adanya perbedaan jenis dan kualitas bahan yang digunakan (Gusmailina et al. ,2003). Hasil analisa laboratorium menunjukkan bahwa kandungan $\mathrm{N}(\%)$ dan $\mathrm{K}_{2} \mathrm{O}(\%)$ limbah penyulingan nilam lebih tinggi dibandingkan arang serbuk gergaji (Tabel 3). 
Tabe13. Sifat kimia limbah penyulingan nilam dan arang serbuk gergaji

Table 3. Chemical characteristics of Nilam distilled waste and charcoal of wood waste

\begin{tabular}{|c|l|c|c|}
\hline \multirow{2}{*}{ No. } & \multirow{2}{*}{ Parameter (Parameters) } & \multicolumn{2}{|c|}{ Kandungan (Content) } \\
\cline { 3 - 4 } & & $\begin{array}{c}\text { Limbah penyulingan } \\
\text { (Distilled waste) }\end{array}$ & $\begin{array}{c}\text { Arang serbuk } \\
\text { gergaji }{ }^{1} \text { (Charcoal of } \\
\text { wood waste) }\end{array}$ \\
\hline 1 & $\mathrm{pH}$ & 8,71 & 10,2 \\
\hline 2 & $\mathrm{C}(\%)$ & 25,67 & 74,16 \\
\hline 3 & $\mathrm{~N}(\%)$ & 1,96 & 0,54 \\
\hline 4 & $\mathrm{~K}_{2} \mathrm{O}(\%)$ & 0,91 & 0,08 \\
\hline 5 & $\mathrm{CaO}(\%)$ & 1,35 & 0,15 \\
\hline
\end{tabular}

Keterangan (Remarks): ${ }^{1}=$ sumber $/$ refer to Gusmailina et al. (2003)

Kandungan unsur hara makro yang dikandung kompos dapat digunakan untuk menilai kualitas kompos. Hakim (2007) menyatakan bahwa kompos yang baik mengandung unsur hara makro nitrogen $>1,5 \%, \mathrm{P}_{2} \mathrm{O}_{5}>1 \%$, dan $\mathrm{K}_{2} \mathrm{O}>1,5 \%$. Sementara itu, Anonim (2007) mengeluarkan standar minimal kandungan unsur hara yang dikandung kompos, diantaranya adalah $\mathrm{N} \geq 2,12 \%, \mathrm{P} \geq 1,3 \%$, dan $\mathrm{C} / \mathrm{N} \leq 20$. Hasil penelitian menunjukan bahwa pada semua dosis orgadec yang dicobakan kandungan unsur hara arkoba nilam pada umumnya memenuhi standar tersebut kecuali kandungan $\mathrm{K}_{2} \mathrm{O}$ yang lebih rendah dari 1,5\%. Dengan hasil ini untuk efisiensi maka dosis orgadec paling rendah (2,5\% dari bobot bahan) disarankan untuk diaplikasikan pada pembuatan arang kompos bioaktif (arkoba) dari limbah penyulingan nilam.

\section{KESIMPULAN DAN SARAN}

1. Berdasarkan perubahan suhu selama pengomposan, tidak ada perbedaan lamanya waktu pengomposan akibat perbedaan dosis orgadec. Pada semua dosis orgadec yang dicobakan (2,5 - 7,5 $\mathrm{kg}$ orgadec/100 $\mathrm{kg}$ bobot ampas penyulingan daun nilam) pengomposan berlangsung selama 33 hari.

2. Aplikasi dosis orgadec yang lebih tinggi tidak menyebabkan lebih tingginya kandungan unsur hara arkoba nilam yang dihasilkan. Pada semua dosis yang dicobakan kandungan unsur hara arkoba nilam yang dihasilkan telah memenuhi standar kualitas kompos menurut Hakim (2007) dan Anonim (2007). Untuk keperluan efisiensi penggunaan bahan bioaktivator dosis orgadec $2,5 \mathrm{~kg} / 100 \mathrm{~kg}$ bobot ampas penyulingan daun nilam merupakan dosis terbaik untuk diaplikasikan.

3. Untuk lebih meningkatkan kandungan unsur hara, penambahan pupuk kandang dan kapur bisa dilakukan pada pembuatan arkoba limbah penyulingan daun nilam. 


\section{DAFTAR PUSTAKA}

Anonim. 2007. Kriteria kualitas. http : //www.menlh.go.id/kompos/aplikasi.php. Diakses 13 April 2007.

Djazuli dan O. Trisilawati. 2004. Pemupukan, pemulsaan dan pemanfaatan limbah nilam untuk peningkatan produktivitas dan mutu nilam. Perkembangan Teknologi TRO 16 (2) : 29 - 37. Balai Penelitian Tanaman Rempah dan Obat. Bogor.

Djuarnani N, Fustian dan Budi . 2005. Cara cepat membuat kompos. Agromedia Pustaka. Jakarta.

Gusmailina, G. Pari dan S. Komarayati. 2003. Pengembangan penggunaan arang untuk rehabilitasi lahan. Buletin Penelitian dan Pengembangan Kehutanan 4 (1) : 21 -30. Badan Penelitian dan Pengembangan Kehuutanan. Jakarta.

Gusmailina, Saepulloh, Mahpudin, S. Komarayati. dan Mad. 2006. Mengenal manfaat arang dan kompos: suatu teknologi inovatif untuk menunjang pembangunan kehutanan yang berkesinambungan. Bahan materi presentasi dalam rangka bimbingan pembuatan arang kompos dari ampas suling nilam di Loka Litbang HHBK Kuok (Tidak dipublikasikan). Pusat Penelitian dan Pengembangan Hasil Hutan. Bogor.

Gusmailina dan Yufnal. 2006. Teknologi alternatif pengelolaan sampah kota menjadi arkoba. Pusat Peneltian dan Pengembangan Hasil Hutan Bahan Materi pada Rapat Pembahasan Masalah Sampah Kota Metropolitan Bandung di Dirjen Cipta Karya Jakarta (Tidak dipublikasikan). Bogor

Hakim, M. 2007. Mengubah sampah menjadi kompos. http://www.pikiranrakyat.com/cetak/2005/1005/20/cakrawala/teknologi02.htm. Diakses tanggal 13 April 2007.

Hardja, S. 2008. Jual pupuk organik/kompos. http://forumiklan.com. Diakses 30 Januari 2008 Simamora, S \& Salundik. 2006. Meningkatkan Kualitas Kompos. Agromedia Pustaka. Jakarta.

Isroi. 2007. Biotekniologi mikroba untuk pertanian organik. http://www kompas.com /kompas-cetak/0412/17/ilpeng/1442850.htm. Diakses tanggal 13 April 2007.

Siregar, C.A. 2007. Effect of charcoal application on the early growth stage of Acacia mangiun and Michelia Montana. Journal of Forestry Research 4 (1) : 19-30. Forestry Research and Development Agency. Jakarta. 